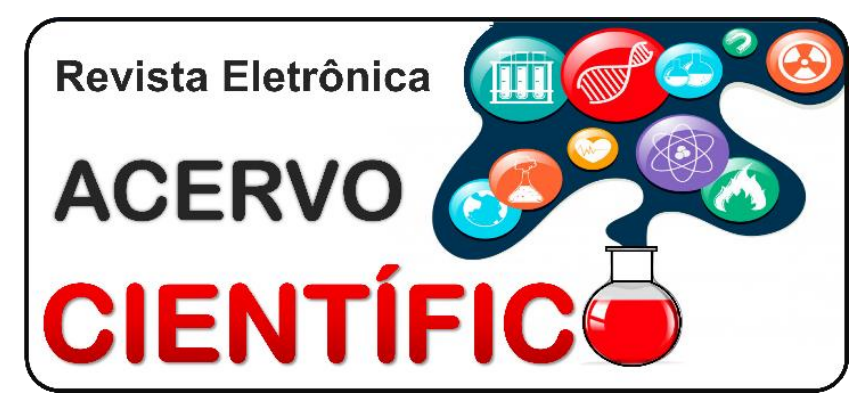

REVISÃO BIBLIOGRÁFICA

Recebido em: 1/2020

Aceito em: 2/2020

Publicado em: 6/2020

\title{
Segurança pública e violência contra a mulher: uma revisão narrativa
}

\author{
Public security and violence against women: a bibliographic review \\ Seguridad pública y violencia contra las mujeres: una revisión bibliográfica \\ Raissa Ribeiro Lima ${ }^{1 *}$.
}

\begin{abstract}
Resumo: Este artigo buscou problematizar as tendências da segurança pública na contemporaneidade e sua atuação no atendimento às mulheres em situação de violência por meio das instituições de segurança. Para o desenvolvimento da pesquisa, foi utilizado material bibliográfico e documental, envolvendo literaturas especializadas sobre o tema. Das análises empreendidas, podemos aferir que a violência contra as mulheres é um fenômeno histórico, resultado das relações sociais desiguais de gênero, classe e étnico-raciais, tendo o sistema patriarcal como fundamento. $O$ atendimento às mulheres em situação de violência não se restringe ao âmbito da segurança pública, mas esta geralmente constitui-se como porta de entrada para as mulheres aos demais serviços de atendimento, por isso é de salutar importância discutir e problematizar essa questão.
\end{abstract}

Palavras-chave: Segurança Pública, Violência contra as mulheres, Atendimento às mulheres.

\begin{abstract}
This article sought to problematize the trends of public security in contemporary times and their role in assisting women in situations of violence through security institutions. For the development of the research, bibliographic and documentary material was used, involving specialized literature on the subject. From the analyzes undertaken, we can see that violence against women is a historical phenomenon, the result of unequal social relations of gender, class and ethnic-racial, with the patriarchal system as the foundation. Assistance to women in situations of violence is not restricted to the scope of public security, but it is generally a gateway for women to other care services, so it is very important to discuss and problematize this issue.
\end{abstract}

Keywords: Public security, Violence against women, Service to women.

Resumen: Este artículo buscó problematizar las tendencias de la seguridad pública en los tiempos contemporáneos y su papel en ayudar a las mujeres en situaciones de violencia a través de las instituciones de seguridad. Para el desarrollo de la investigación, se utilizó material bibliográfico y documental, que incluyó literatura especializada sobre el tema. A partir de los análisis realizados, podemos ver que la violencia contra las mujeres es un fenómeno histórico, el resultado de relaciones sociales desiguales de género, clase y etnia racial, con el sistema patriarcal como base. La asistencia a las mujeres en situaciones de violencia no se limita al alcance de la seguridad pública, pero generalmente es una puerta de entrada para las mujeres a otros servicios de atención, por lo que es muy importante discutir y problematizar este tema.

Palabras clave: Seguridad Pública, Violencia contra la mujer, Servicio a la mujer.

1Universidade Federal do Amazonas (UFAM), Parintins - AM. *E-mail: raissaribeirolima15@gmail.com 


\section{INTRODUÇÃO}

A violência contra a mulher é um fenômeno histórico, resultado das relações sociais desiguais de gênero, classe e étnico-raciais, tendo o sistema patriarcal como fundamento (SAFFIOTI HBI, 2004). A lógica que estrutura este sistema é de privilégio e dominação masculinos relacionados a subalternização e invisibilidade das mulheres e do que é associado, considerado ou identificado como feminino, a exemplo dos travestis e das mulheres transexuais que são sujeitos que transgredem o "modelo" patriarcal do "macho", mas também sofrem sua opressão, pois, são associados ou considerados femininos (CISNE M e SANTOS SMM, 2018).

No Brasil, a partir da década de 1970, a violência contra as mulheres passou a ser discutida por movimentos de mulheres e feministas, com um caráter mais político e organizado, tornando-se tema central de suas reivindicações nas décadas posteriores (IZUMINO WP, 2004). Na década de 1980, grupos feministas começaram a se organizar com outros movimentos no combate à violência contra as mulheres, cobrando do Estado mecanismos que amparassem as mulheres em situação de violência (Idem). Em resposta a estas manifestações, foi criada no ano de 1985, em São Paulo, a primeira Delegacia de Defesa à Mulher (DDM) (Idem). A criação da delegacia especializada foi uma experiência pioneira no mundo, e desde sua instalação tem ocupado posição central nos debates a respeito da violência contra a mulher. Avançava-se, portanto, na criminalização da violência.

Particularmente, hoje, existe um grande debate sobre a violência contra as mulheres e segurança, de modo que o poder público e a comunidade acadêmica são chamados a debater e problematizar esses temas, ainda mais em um contexto de destruição das políticas públicas para as mulheres. Destacamos a importância da produção científica na área da segurança pública pois, além de constituir como umas das principais demandas sociais é também um dos principais temas de estudo da atualidade em várias áreas do conhecimento, implicando em multiplicidade de abordagens sobre o tema. Estudar temas como este, pode contribuir para a reflexão sobre a articulação dos serviços de atendimento às mulheres em situação de violência e para instrumentalizar a atuação dos profissionais da área, podendo fornecer subsídios para a realização de um atendimento humanizado e de qualidade às mulheres nestas instituições.

Nessa direção, o artigo problematiza de forma preliminar e exploratória as tendências da segurança pública na contemporaneidade e sua atuação no atendimento às mulheres em situação de violência por meio das instituições de segurança no intuito de apreender como estão estruturadas essas relações e como isso reflete no atendimento às mulheres em situação de violência.

\section{REVISÃO BIBLIOGRÁFICA}

\section{O patriarcado-racista-capitalista como fundamento da violência contra a mulheres}

O fenômeno da violência, em particular a violência contra as mulheres, possui múltiplas significações e determinações sócio-históricas, tendo como fundamento o patriarcado-racista-capitalista, um sistema que oprime, humilha, desvaloriza e desiguala as mulheres (BARROSO MF, 2018). Segundo Saffioti HIB (2004) o patriarcado é um sistema que precede ao capitalismo, "refere-se a milênios da história mais próxima, período no qual se implantou uma hierarquia entre homens e mulheres, com primazia masculina". Nessa direção, Stearns PN (2015) ratifica que a partir dos contatos e das trocas, a agricultura e as civilizações se desenvolveram, foram se estabelecendo as relações entre homens e mulheres, a determinação de papéis e as definições dos atributos de cada sexo, pondo fim à igualdade entre homens e mulheres existente nas sociedades primitivas comunais.

Saffioti HIB (1992) analisa a família como lócus privilegiado do patriarcado, mas não o único. Para a autora o patriarcado se apresenta como um sistema de dominação-exploração que perpassa o âmbito familiar atingindo todas as esferas sociais e políticas da sociedade (Idem). No campo dos estudos feministas, Almeida JP (2010) afirma que o patriarcado está presente em diversas instituições sociais, "desde a família ao Estado, apresentando-se em todos os espaços da sociedade". Sendo assim, a família é parte dessa estrutura patriarcal, mas não a única, pois o patriarcado se expande em toda a vida social, na produção e reprodução da vida, "estando inclusive, inculcado no inconsciente de homens e mulheres individualmente e no coletivo enquanto categorias sociais" (ALVES LN, et al., 2016). 
Partimos, portanto, do pressuposto de que as violências não resultam das relações individuais, mas, sobretudo, são constituídas pelas relações sociais de sexo/gênero, raça/etnia e classe que consubstanciam a sociedade patriarcal-racista-capitalista (BARROSO MF, 2019). As análises de Barroso MF (2019), Cisne M e Santos SS (2018) e Saffioti HIB (2004) indicam que as ordens de gênero, de raça/etnia e de classe social estão unificadas por uma estrutura de poder e devem ser analisadas de forma consubstanciada e não separadas. Barroso MF (2019) pondera que, de um lado, o patriarcado penetrou em todas as esferas da vida social, não se restringindo apenas ao âmbito doméstico, e, de outro lado, o capitalismo também mercantilizou todas as relações sociais. Da mesma forma, a raça/etnia, com tudo que implica em termos de discriminação, imprimiu sua marca no corpo social por inteiro (Idem). Essas três relações, por serem permeadas pela exploração da força de trabalho, são estruturantes da totalidade da vida social, do sistema patriarcal-racistacapitalista (CISNE M e SANTOS SMM, 2018).

Nessa direção, Alves LN, et al. (2016) defendem que a propagação da ideologia dominante é a base fundamental para a reprodução do sistema patriarcal-racista-capitalista que naturaliza e despercebe a opressão e exploração, fazendo com que a condição das mulheres pareça ser natural ou imutável. Para os autores, a exploração do trabalho se dá em detrimento de uma classe menos favorecida - a classe trabalhadora -, onde os mais explorados/atingidos são as mulheres pobres e negras (Idem). A mulher negra, portanto, no contexto dessas relações patriarcais e racistas, encontra-se na pior escala social, "ocupando, por exemplo, os postos de trabalho mais precarizados e mal remunerados, e expostas a maiores situações de violências" (CISNE e SANTOS, 2018).

Segundo o IBGE (2015), as mulheres permanecem, ainda, com rendimento médio inferior ao dos homens, o equivalente a $76,5 \%$. Quando analisamos os dados segregados por raça/cor, eles apontam que 0 rendimento médio das mulheres negras equivale a $35 \%$ do rendimento médio dos homens brancos, o que aponta para a desigualdade abissal quando consideramos a combinação de sexo e raça (Idem). Esses são alguns dos indicadores da incorporação do patriarcado e do racismo na formação do capitalismo no Brasil que perduram até os dias de hoje.

A violência contra a mulher, no Brasil, atinge índices alarmantes. Segundo os registros de atendimento feitos à Central de Atendimento à Mulher - Ligue 180 (2015), de janeiro a outubro de 2015, do total de atendimentos, 63.090 foram relatos de violência, dos quais $58,55 \%$ foram cometidos contra mulheres negras, enquanto $40,48 \%$ foram cometidos contra mulheres brancas, $0,52 \%$ cometidos contra mulheres amarelas e 0,45 contra mulheres indígenas. A ausência de dados sobre a violência contra as mulheres indígenas segundo Barroso MF (2015) contribui para análises fragilizadas que reforçam ideologias de dominação, colaborando para a invisibilidade dos sujeitos. A autora destaca ainda que se trata de um tema que não possui visibilidade nos institutos de pesquisa, nas instituições da segurança pública, nem na ciência e que os registros na maioria das vezes são pontuais, acontecendo em eventos e encontros em que as mulheres indígenas realizam as denúncias (Idem).

Para ilustrar ainda mais o cenário da violência contra as mulheres brasileiras, os dados do Dossiê Violência contra as Mulheres, do Instituto Patrícia Galvão apresenta uma compilação de dados sobre o fenômeno da violência contra as mulheres, onde há: 5 espancamentos a cada 2 minutos (FUNDAÇÃO PERSEU ABRAMO, 2010); 1 estupro a cada 11 minutos (ANUÁRIO DA SEGURANÇA PÚBLICA, 2015); 1 feminicídio a cada 90 minutos (IPEA, 2013); 179 relatos de agressão por dia (BALANÇO LIGUE 180, 2015); e 13 feminicídios por dia em 2013 (MAPA DA VIOLÊNCIA, 2015). Os dados apontam ainda que 3 em cada 5 mulheres jovens já sofreram violência em relacionamentos (INSTITUTO AVON/DATA POPUPLAR, 2015). O dado sobre estupro revela que esta prática não foi superada com o fim da escravidão, evidenciando a estrutura patriarcal e racista de controle sobre os corpos das mulheres ainda persistentes (CISNE M e SANTOS SMM, 2018).

As discussões revelam que a história patriarcal e escravista não se encerrou no período colonial do Brasil. As marcas patriarcais e racistas se expressam também através da desigualdade entre homens e mulheres no mundo do trabalho, da divisão sexual e racial, das jornadas intensivas, extensivas e intermitentes de trabalho (ÁVILA MB, 2009) dentro e fora de casa, nos alarmantes índices de violência contra a mulher e contra a população LGBT (CISNE M e SANTOS MSS, 2018). 
A partir dos dados e discussões, podemos apreender que, embora o patriarcado atinja de forma estrutural a sociedade, este traz implicações diretamente e de forma particular para a vida das mulheres, e que a dimensão étnico-racial imprime uma maior "vulnerabilidade" das mulheres negras e indígenas às diversas expressões da violência. Revelam as raízes de uma sociedade historicamente assentada no patriarcado e no racismo, na qual o capitalismo brasileiro se desenvolveu, impactando diretamente nas condições de vida e de trabalho das mulheres. Os dados levam à necessidade de pensar não apenas alternativas de enfrentamento à violência contra as mulheres, mas entender as bases patriarcais-racistas-capitalistas que sustentam a permanência dessa violência.

\section{Segurança Pública $e \mathrm{o}$ atendimento às mulheres em situação de violência}

O sistema capitalista tem deixado significativos efeitos na configuração da sociedade perfazendo a forma como esta se estrutura e se transforma ao longo dos tempos (BERINGH ER e BOSCHETTI I 2009). Em consideração a isso emergiram as Políticas Sociais Públicas (Idem). Estas se apresentam, no contexto do capital, formas de enfrentamento e respostas às manifestações da questão social que emerge a partir das contradições entre capital e trabalho (Idem). Dentre tais políticas ressalta-se a Política de Segurança Pública, insistentemente problematizada e discutida pela mídia, Estado e sociedade civil.

Para Carvalho VA e Silva MRF (2011) "a segurança pública é considerada uma demanda social que necessita de estruturas estatais e demais organizações da sociedade para ser efetivada". O sistema de segurança pública é composto por instituições ou órgãos estatais que se materializam através dos planos e programas que são responsáveis pela adoção de ações direcionadas a segurança individual e coletiva da sociedade (Idem).

Carvalho VA e Silva MRF (2011) elucidam ainda que apesar de haver uma redução da intervenção do Estado no âmbito econômico e social, na segurança pública tem ocorrido uma ampliação de investimentos nos instrumentos de controle sobre a sociedade. Isso porque "na esfera do Estado neoliberal, o Estado penal torna-se aliado, pela via de ações fortalecedoras do controle dos processos de "marginalização" econômica e social" (CARVALHO VA e SILVA MRF, 2011).

Conforme salienta Wacquant $L$ (2008) esse processo é denominado como criminalização da pobreza e da miséria. E está relacionado à "[...] insegurança social gerada em toda parte pela dessocialização do trabalho assalariado, o recuo das proteções coletivas e a 'mercantilização' das relações humanas" (WACQUANT L, 2008). Para o autor o paradoxo existente entre o menos Estado econômico e social, subsidiado pelo neoliberalismo e o mais Estado policial e penitenciário, concretiza e fomenta a insegurança social generalizada da qual somos, simultaneamente vítimas e algozes (Idem).

Portanto, a ascensão do "Estado Penal" decorre da precarização do trabalho e deterioração das relações sociais de produção, impostas pelo neoliberalismo, que atende aos interesses do mercado. Atesta-se a afirmação feita por Carvalho VA e Silva MRF (2011), 'temos, assim, um 'Estado para os pobres', com menos assistência e mais controle e vigilância e um 'Estado para os ricos', que possibilita menos controle sobre a reprodução econômica", direcionando assim, as formas de penalização a sujeitos diferenciados (Idem). Tudo isso exposto de maneira exagerada pela mídia através de "relatos por vezes exagerados das práticas de delitos cometidos, na sua grande maioria por pobres, enaltecios sob a ótica que vislumbra a responsabilização do culpado e a necessidade de se ampliar o poder de punir do Estado" (CUNHA CD, 2013), não considerando que este, ao lado do mercado, é o maior provedor da violência estrutural que compõe o contexto contemporâneo (WACQUANT L, 2008). Assim, os governos contribuem para que o papel do Estado sirva aos poucos donos do poder em detrimento da soberania do povo ao adotarem ações de repressão à criminalidade através da institucionalização de processos de criminalização de segmentos sociais e exclusão das possibilidades do mercado (CARVALHO AD e SILVA MRF, 2011).

Campos $\mathrm{CH}$ (1999) ratifica que a criminologia crítica questiona o sistema penal e revela um dos principais pilares sobre os quais se assenta a criminalidade: a seletividade. Para a autora "o sistema penal passa a ter a função social de reproduzir as relações sociais e de manter a estrutura vertical da sociedade e os processos de marginalização" (CAMPOS CH, 1999), sendo visto como um violador de direitos. 
No que tange ao debate sobre as mulheres, Andrade VRP (1999), referência no debate sobre criminologia crítica feminista, analisa o Estado Penal como um meio ineficaz para a proteção das mulheres contra a violência, uma vez que este duplica a violência exercida contra elas e as divide, sendo uma estratégia excludente, que afeta a própria unidade do movimento de mulheres. Isto porque se trata de um subsistema de controle social, seletivo e desigual, tanto de homens como de mulheres e porque é, ele próprio um sistema de violência institucional, que exerce seu poder e seu impacto sobre as vítimas (Idem).

Segundo a autora, o que as mulheres esperam do sistema penal é a punição da violência, o que conduz a uma situação paradoxal, pois essa demanda pelo sistema penal acaba por reunir o movimento de mulheres, que é um dos movimentos mais progressistas do país, com um dos movimentos mais conservadores e reacionários, que é o movimento de "Lei e Ordem" (ANDRADE VRP, 1999). Ambos acabam se reunindo pela ideia de mais punição e mais repressão.

A autora conclui que "o discurso feminista que visa a criminalização da violência como um fim, encontrase nessa perspectiva, imerso na reprodução da mesma matriz (patriarcal e jurídica) da qual, faz a crítica, num movimento extraordinariamente circular" (ANDRADE VRP, 1999). Ou seja, segmentos do movimento feminista buscam libertar-se da opressão masculina recorrendo à proteção de um sistema demonstradamente classista e sexista (Idem). Este duplica a violência e divide as mulheres, sendo uma estratégia excludente, que afeta a própria unidade do movimento de mulheres. Isto porque se trata de um subsistema de controle social, seletivo e desigual, tanto de homens como de mulheres e porque é, ele próprio um sistema de violência institucional, que exerce seu poder e seu impacto sobre as vítimas.

\section{CONSIDERAÇÕES FINAIS}

A partir das discussões, podemos aferir que, o sistema penal brasileiro aparece como um meio ineficaz para a proteção das mulheres, uma vez que essas instituições se inscrevem em uma história de repressão e criminalização. E isso recai sobre o sistema de segurança pública, principalmente nas instituições que atendem as mulheres vítimas de violência, pois cotidianamente, as instituições policiais são buscadas por mulheres que vivem situações de violência, esperando uma ação mediadora da polícia e o que encontram como resposta à expectativa de proteção que têm em relação à ação policial são o descaso e a omissão, em relação as situações de violência. Contudo, mesmo entendendo dessa forma, faz-se importante reconhecer espaços/instituições, como as Delegacias Especializadas de Atendimento às Mulheres (DEAMs) - resultado das lutas das mulheres pelo reconhecimento e criminalização da violência -, que muitas vezes é o único espaço considerado especializado no atendimento às mulheres no âmbito da Segurança Pública.

\section{AGRADECIMENTOS E FINANCIAMENTO}

Agradecemos a Universidade Federal do Amazonas/UFAM por possibilitar a realização de um curso de imensa qualidade, com professores qualificados, bem como pelo fornecimento de toda a infraestrutura para a realização da pesquisa. Estendemos os agradecimentos também a todos/as que de forma direta ou indiretamente contribuíram para a realização desse trabalho.

\section{REFERÊNCIAS}

1. ALMEIDA JP. As multifaces do patriarcado: uma análise das relações de gênero nas famílias homoafetivas. Dissertação (Mestrado em Serviço Social). Universidade Federal de Pernambuco, Recife, 2010; 116p.

2. ALVES LN, et al. A relação de dominação/exploração no capitalismo patriarcal: apropriação da vida das mulheres. Anais do 4ํㅗ Simpósio mineiro de assistentes sociais: 80 anos de serviço social tendências e desafios, 2016; 4(1): 114.

3. ANDRADE VRP. Criminologia e Feminismo: da mulher como vítima à mulher como sujeito. In: CAMPOS, CH. (Org.). Criminologia e Feminismo. Porto Alegre: Editora Sulina, 1999; 122p.

4. ANUÁRIO DA SEGURANÇA PÚBLICA. 2015. In: Fórum Brasileiro de Segurança Pública. Disponível em:https://www.google.com/search?q=anuario+da+seguran\%C3\%A7a+publica+2015\&oq=anuario\&aqs=chrome. 1.6 9i57j35i39j0l5j69i60.3421j0j4\&sourceid=chrome\&ie=UTF-8. Acesso em: 15 nov. 2019. 
5. ÁVILA MB. O tempo de trabalho das empregadas domésticas: tensões entre dominação/exploração e resistência. Tese (Doutorado em Sociologia). Universidade Federal de Pernambuco, Recife, 2009; 315p.

6. BALANÇO LIGUE 180. 2015. In: Central de Atendimento à mulher - Secretaria de Políticas para as Mulheres. Disponível em: https://dossies.agenciapatriciagalvao.org.br/dados-e-fontes/pesquisa/ligue-180-balanco-10-anos-dacentral-de-atendimento-a-mulher-spm-2015/. Acesso em: 15 nov. 2019.

7. BARROSO MF. "O começo do fim do mundo": violência estrutural contra mulheres no contexto da hidrelétrica de Belo Monte. Tese (Doutorado em Serviço Social) - Faculdade de Serviço Social. Universidade do Estado do Rio de Janeiro, 2018; 385p.

8. BARROSO MF. Rotas críticas das mulheres Sateré-Mawé no enfrentamento à violência doméstica: novos marcadores de gênero no contexto indígena. Manaus: Edua, 2015; 155p.

9. BARROSO MF. Violência estrutural contra mulheres em Belo Monte: o que os dados oficiais (não) revelam. Revista Em Pauta, 2019; 43(17): 140-154.

10. BEHRING ER, BOSCHETTI I. Política social: fundamentos e história. São Paulo: Cortez, 2009; $216 \mathrm{p}$.

11. CAMPOS CH. Introdução. In: CAMPOS, CH. (Org.). Criminologia e Feminismo. Porto Alegre: Editora Sulina, 1999; 122p.

12. CARVALHO VA, SILVA MRF. Política de segurança pública no Brasil: avanços, limites e desafios. Revista Katális. Florianópolis, 2011; 14(1): 59-67.

13. CISNE M, SANTOS SMM. Feminismo, diversidade sexual e serviço social. São Paulo: Cortez, 2018; $208 p$.

14. CUNHA CD. A construção de um novo paradigma de segurança pública como política social: a experiência da política de prevenção à criminalidade no Estado de Minas Gerais. Anais do III simpósio mineiro de assistentes sociais: expressões socioculturais da crise do capital e as implicações para a garantia dos direitos e para o serviço social, 2013; 3(1): 1-24.

15. FUNDAÇÃO PERSEU ABRAMO. 2010. Mulheres brasileiras e gênero nos espaços público e privado. Disponível em: https://fpabramo.org.br/publicacoes/publicacao/pesquisa-mulheres-brasileiras-e-genero-nos-espacos-publico-eprivado-2010/. Acesso em: 15 nov. 2019.

16. INSTITUTO AVON/DATA POPULAR. Violência contra a mulher no ambiente universitário, 2015. Disponível em: http://www.ouvidoria.ufscar.br/arquivos/PesquisalnstitutoAvonV9_FINAL_Bx20151.pdf. Acesso em: 15 nov. 2019.

17. INSTITUTO BRASILEIRO DE GEOGRAFIA E ESTATÍSTICA. 2015. Síntese de indicadores sociais: uma análise das condições de vida da população brasileira. Disponível em: https://www.google.com/search?q=ibge+2015+sintese+de+indicadores\&oq=ibge+2015+sintese+de+indicadores\&aq $\mathrm{S}=$ chrome..69i57.11228j0j4\&sourceid=chrome\&ie=UTF-8. Acesso em: 15 nov. 2019.

18. INSTITUTO DE PESQUISA ECONÔMICA APLICADA. 2013. Violência contra a mulher: feminicídios no Brasil. Disponível em: http://www.ipea.gov.br/portal/index.php?option=com_content\&id=19873. Acesso em: 15 nov. 2019.

19. IZUMINO WP. Violência contra a mulher no Brasil: acesso à justiça e a construção da cidadania de gênero. Anais do VIII Congresso luso-afro-brasileiro de ciências sociais: a questão social no novo milênio, 2004; 8(1): 1-18.

20. MORGANTE MM e NADER MB. O patriarcado nos estudos feministas: um debate teórico. Anais do XVI Encontro regional de história do Anpuh-Rio: saberes e práticas científicas, 2014; 15(1): 1-10.

21. SAFFIOTI HIB. Gênero, patriarcado, violência. São Paulo: Editora Fundação Perseu Abramo, 2004; 152p.

22. SAFFIOTI HIB. Rearticulando gênero e classe social. In: OLIVEIRA, A.; BRUSCINI, C. (Org.). Uma questão de gênero. Rio de Janeiro: Rosa dos Tempos 1992; 183-215p.

23. SILVA MV. Violência contra a mulher: quem mete a colher? São Paulo: Cortez, 1992; 180p.

24. STEARNS PN. 2015. As origens das civilizações e do patriarcado. Disponível em http:www.editoracontexto.com.br/blogas-origens-das-civilizacoes-e-do-patriarcado/. Acesso em 15 ago. 2019.

25. WACQUANT L. As prisões da miséria. São Paulo: Zahar, 2008; 208p.

26. WAISELFIZ JJ. 2015. Mapa da Violência 2015: homicídio de mulheres no Brasil. Disponível em:https://www.google.com/search?q=mapa+da+viol\%C3\%AAncia+2015\&oq=mapa+da+viol\%C3\%AAncia+2015\&a qs=chrome..69i57.11965j0j7\&sourceid=chrome\&ie=UTF-8. Acesso em: 15 nov. 2019. 